\title{
Recurrent herpes zoster with IgD deposits, multinucleated keratinocytes and overexpression of galectin and glypican 3 in a patient with SARS-COVID-19 infection
}

\section{Ana Maria Abreu Velez ${ }^{1}$, Amanda Bortle Thomason², Billie L. Jackson ${ }^{3}$, Michael S. Howard'}

${ }^{1}$ Georgia Dermatopathology Associates, Atlanta, Georgia, USA, ${ }^{2}$ D.O. Student, Philadelphia College of Osteopathic Medicine/Georgia Campus, Suwanee, Georgia, USA, ${ }^{3}$ Billie L. Jackson, M.D., Dermatologist, Macon, Georgia, USA.

Corresponding author: Amanda Bortle Thomason, D.O, E-mail: amandabor@pcom.edu

\begin{abstract}
The novel coronavirus disease (COVID-19) that currently plagues the world and caused by SARS-CoV-2, has spread internationally since late 2019. The dermatologic manifestations of this virus are currently being identified. We describe a 73-year-old Caucasian female who presented to many physicians for recurrent Herpes zoster episodes that persisted, despite treatment with multiple antiviral medications. The patient was diagnosed with COVID-19 before an onset of vesicular pustular lesions. The clinical diagnoses were recurrent herpes zoster and recurrent varicella. A skin biopsy was obtained and stained with hematoxylin and eosin to confirm a diagnosis. Immunohistochemical stains for Ki-67, Phospho-Histone H3, galectin 3, glypican and $\mathrm{IgD}$ were positive in multinucleated cells of the skin, where the viral lesions were detected. Recidivated herpes zoster and varicella are currently being clinically associated with COVID- 19; the abnormal immune response in patients with COVID-19 may be due to the overexpression of molecules that facilitate the outbreak of these viruses.
\end{abstract}

Keywords: Herpes zoster; Varicella; COVID 19; IgD; Galectin and glypican 3

\section{INTRODUCTION}

In December 2019, a severe acute respiratory syndrome coronavirus 2 (SARS-CoV-2) presented clinically in Wuhan, China. It was first reported from a group of patients who suddenly developed severe pneumonia [1]. The SARS-CoV-2 virus is part of the coronavirus family, and this newly discovered strain is a RNA, single stranded, encapsulated virus [2]. The associated human disease, COVID-19, has spread globally and is responsible for an ongoing pandemic that has claimed thousands of lives [1]. Skin related conditions due to COVID 19 have been reported; the most common presentations seem to be acral lesions resembling pseudo-chilblains (perniosis like) in $40.4 \%$ of cases, occurring in young adults. Other manifestations include erythematous, maculopapular rashes affecting approximately $21.3 \%$ of adult patients, vesicular "rashes" affecting about $13.0 \%$ of middleaged adults, and urticarial rashes in $10.9 \%$ of adults. Vascular rashes reminiscent of livedo or purpura were uncommon (4\% of cases), mostly seen in elderly patients. In minors, the most common dermatologic manifestation was erythema multiforme-like eruptions in about $4 \%$ of the cases [3].

\section{CASE REPORT}

A 73-year-old Caucasian female presented to her primary care physician for recurrent, vesicular rashes.

\footnotetext{
How to cite this article: Abreu Velez AM, Thomason AB, Jackson BL, Howard MS. Recurrent herpes zoster with IgD deposits, multinucleated keratinocytes and overexpression of galectin and glypican 3 in a patient with SARS-COVID-19 infection. Our Dermatol Online. 2022;13(1):41-44.

Submission: 22.09.2021; Acceptance: 11.11.2021

DOI: 10.7241/ourd.20221.8
} 
In addition to her viral blister episodes, the patient had chronic solar skin damage with a history of several pre-cancers such as actinic keratosis; also, a history of inflamed seborrheic keratoses. Additionally, she had been treated for squamous cell carcinoma on the chin, right cheek, and chest as well as basal cell carcinoma on the right upper lip. She also had presented with four previous dysplastic nevi on her back. Of interest, the patient reported that her last episode of oral HSV-l was six years prior to the current presentation; it was treated with antiviral medications. She also reported two episodes of chickenpox in her childhood, at the ages of 4 and 7. She had never taken the shingles vaccine but did have a mild outbreak of shingles in 1990 on her left lower back with mild pain; it resolved quickly. The patient's chemical laboratory tests displayed mildly abnormal results such as phosphorus $2.4 \mathrm{~L}$ (3-4.5 mg/dl), glucose 112 high (H) (66-99 mg/dl), Hemoglobin Alc 6.1\%, ALT 63 H (0-32iu/L), AST $60 \mathrm{H}(0-40 \mathrm{iu} / \mathrm{L})$; her ANA was negative. The patient was taking Synthroid ${ }^{\circledR}, \operatorname{Losartan}^{\circledR}, \mathrm{Welchol}^{\circledR}, \mathrm{Cartia}^{\circledR}$, Vitamin B12, Vitamin D and Ambien ${ }^{\circledR}$, with no recent changes in her medications or dosages.

The patient's first outbreak started 3 months after a proven COVID-19 infection, using the antibody test for SARS-CoV-2-Antibody showing IgM negative, IgA negative, and IgG positive findings. The rash started as grouped, painful vesicles with a severe burning sensation on the back. On physical examination, the back rash displayed T10 dermatome distributed vesicles, grouped together. Upon healing, the back retained with an erythematous patch on the left side. The clinical diagnosis was herpes zoster. The dermatologist obtained a clear image of the initial site on the back, post-treatment (Fig. la). Gladdin ${ }^{\circledR}$ was prescribed for the herpes zoster followed by Valtrex ${ }^{\circledR}$ for seven days. In less than a month, the patient presented with an outbreak of clinical varicella on the abdomen (Fig. 1b). During the three succeeding months, a second and third similar "double" outbreaks erupted, with about one-month lapses between the episodes. In addition to the above-mentioned antiviral regimen, a Myers cocktail supplement was given to boost the immune system (Magnesium, Calcium, and B vitamins via slow IV push). Prednisone $10 \mathrm{mg}$ for three days was added as therapy. Due to a superinfection with Gram positive bacteria, the lesions were cleaned with a topical antiseptic.

A skin biopsy of the affected area from the left abdomen was examined with hematoxylin and eosin

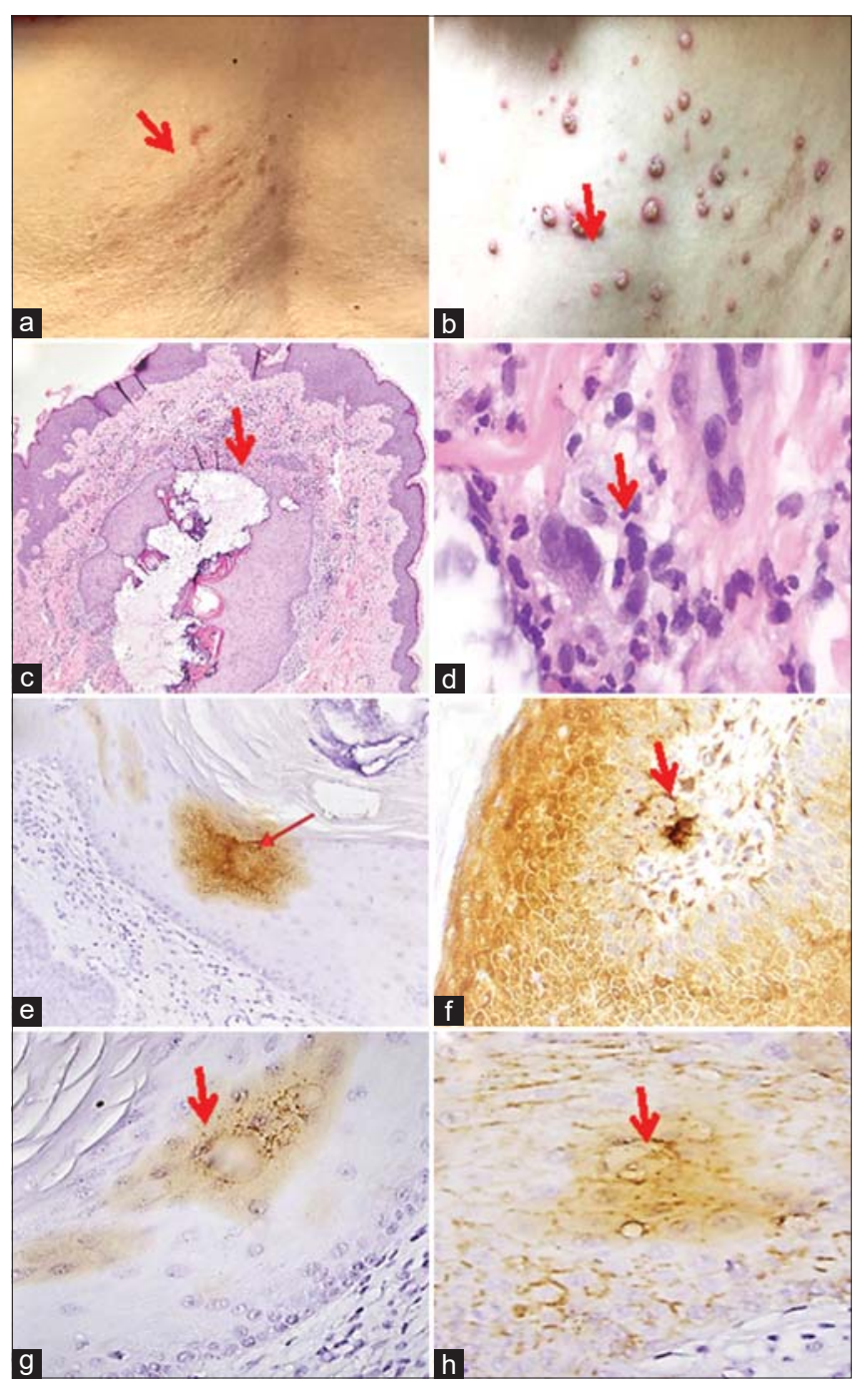

Figure 1: (a) A herpes zoster post-treatment lesion, showing hyperpigmented marks on the back, following the T10 dermatome (red arrow). (b) Representative varicella lesions in the abdomen (red arrow). (c) An H\&E stain showing the blister in the center with some re-epithelization and a dilatation of the dermal vessels with dermal inflammation and edema surrounding the central ulcerated area (red arrow) (40X). (d) H\&E displaying a herpetic keratinocyte with multinucleation, marginalization and molding of the nuclear chromatin (red arrow) (1000X). (e) Positive IHC staining with galectin 3 in multinucleated herpetic cells showing damage to the cells (brown staining; red arrow) (400X). (f) Positive IHC staining with glypican 3, showing staining of epidermal keratinocytes, and a large, infected keratinocyte (red arrow) (brown staining) (600X). (g) Positive IHC staining with IgD in multinucleated herpetic cells (brown staining; red arrow) (600X). (h) Positive IHC staining with CD138 in multinucleated herpetic cells and some staining between keratinocytes (brown staining; red arrow) (600X).

(H\&E) and with Leica immunohistochemical (IHC) stains for glypican-3(1G12 Mab) Cat. No. PA0800; galectin 3, Cat. No. PA0238; Phospho-Histone H3 (PHH3) (Polyclonal) Cat. No. PA0817; Ki67 (K2) Cat. No. PA0230; CD138 (syndecan) Cat. No. PA0088, and IgD, Cat. No. PA006(all antibodies were from Novocastra-Leica Biosystem's, Buffalo Grove, Illinois, 
USA). The IHC stains were performed as previously described [4]. The H\&E sections displayed areas in the epidermis with blistering at multiple levels and with reepithelization (Fig. 1c). Several keratinocytes displayed ballooning degeneration, and their nuclei showed variable multinucleation, molding and margination of chromatin. In addition, in the papillary dermis, dilated blood vessels were observed. A mixed inflammatory infiltrate was present within the dermis, featuring areas with numerous neutrophils (in some patchy areas), lymphocytes and histocytes. The histologic features were representative of a varicella zoster infection. The Gram stain showed some Gram-positive cocci and neutrophils within the previously noted patchy areas. The IHC stains demonstrated that the multinucleated keratinocytes strongly expressed galectin (Fig. le), glypican 3 (Fig. lf), IgD (Fig. lg) and CD138 (Fig. 1h). The IHC stains with and PHHP-3 and Ki-67 showed increased staining of basaloid keratinocytes subjacent to the herpetic cells, indicating an acceleration in cell replication.

\section{DISCUSSION}

Skin rashes associated with COVID-19 have primarily presented with erythematous, urticarial, and vesicular (chicken pox-like or varicelliform) manifestations [3-5]. Vascular manifestations such as petechiae and livedo reticularis have been noted. Reactivation of oral herpes virus (HSV-1) lesions have also been observed $[3,5]$. There have been recent clinical reports of herpes zoster in patients affected by COVID-19 [6-8]. Herpes zoster is caused by the varicellazoster virus (VZV), a DNA virus of the Herpesviridae (HHV-3) family. The clinical presentation can be recurrent and presents in dermatomes that are likely dormant at their corresponding dorsal root ganglia [6-8]. Herpes zoster can occur in immunocompromised patients and patients experiencing stress or increased sunlight exposure. A common associated symptom is postherpetic neuralgia, which is characterized as sensitive, burning, and painful skin in the same area where the rash once was but has clinically resolved with the neuralgia persisting [6-9]. SARS-CoV-2 affects many systems including the pulmonary, circulatory, hematologic, immunologic, and other systems/organs that differ from many of the common responses seen when similar viruses infect humans [1-3].

Varicella-zoster virus re-activation increases during aging, and herpesviruses are known to reactivate in response to different kinds of stress. In the current case, the herpes zoster virus was likely reactivated by COVID-19. Recent studies have demonstrated the importance of understanding the complex, virusspecific immune response of SARS-CoV-2 in the effort to control and treat COVID-19. The immune response consists of essential components of $\mathrm{B}$ and $\mathrm{T}$ cells and antibodies. It has been reported that when SARS-CoV-2 enters the body, the innate immune system elicits a broad and unspecific attack against the virus [10]. There is an intensifying response from many signaling molecules that result in inflammation, provoking the adaptive immune system to mount a precise attack against the virus. The adaptive immune system response is composed of three major lymphocyte types: $\mathrm{B}$ cells that produce antibodies, CD4 positive T cells (helper T cells) and CD8 positive T cells (cytotoxic T cells and killer T cells) [10]. In our case, the medical history of multiple pre-cancerous and cancerous skin lesions suggests a decrease in the $\mathrm{T}$ cell response. Most pertinent, the patient experienced multiple, prolonged herpes zoster and varicella episodes that suggest SARS$\mathrm{CoV}-2$ diminished the immune response, primarily of the $\mathrm{T}$ cell pathway.

Of interest, we detected that glypican 3 and syndecan (CD138) were overexpressed in the herpetic keratinocytes. These two molecules project glycosaminoglycan chains onto cell surfaces, that provide initial docking sites for viruses to bind to eukaryotic cells. Herpesviruses seem to use heparan sulfate to assist in cell entry [11-13]. Glypican 3 has other important functions in cellular signaling, tissue repair and inflammation. We speculate that both the VZV and the HHV-3 virus are overexpressing glypican 3 for putative virus entry, and therefore increasing keratinocyte cell signaling, repair and inflammation [11-13]. IgD was also present on the lesional cells. This antibody is usually co-expressed with IgM, another cell surface antibody. Previous studies have shown that $\operatorname{IgD}$ signaling is likely triggered by repetitive multivalent immunogens. In our case, the presence of $\operatorname{IgD}$ is likely due to the associated viral infections of VZV and HHV-3 [14].

\section{CONCLUSIONS}

As the virus has detrimentally impacted the entire world, clinicians and scientists are still gathering data to explain not only the viral transmission, cellular pathway, and proper treatments but also to 
detect early symptoms of the disease and all effected organ systems. While this patient is considered high risk for reactivation of herpes zoster due to her age alone, we cannot rule out that her recent exposure to COVID-19 contributed to the sixty-plus-day duration of zoster rash. We conclude that repetitive outbreaks of herpes zoster and varicella, in a patient with previous COVID-19 exposure, are part of the dermatological manifestation of this disease. This disseminated herpes reactivation illustrates the unpredictable presentation of the virus, with the back lesion's characteristic of classic shingles and abdominal lesions simulating chickenpox, with a non-dermatomal distribution pattern. The glypican 3 and CD138 biomarkers found in the biopsy sample support the concept that not only is the host immune system altered by the herpes infections, but also the possibility that their overexpression is due to the prior Coronavirus exposure. As more clinical findings are being reported before, during, and after COVID-19 exposure it is critical to consider these manifestations to fully understand this disease process.

\section{Consent}

The examination of the patient was conducted according to the principles of the Declaration of Helsinki. The authors certify that they have obtained all appropriate patient consent forms, in which the patients gave their consent for images. Our Dermatol Online 3.2021269 and other clinical information to be included in the journal. The patients understand that their names and initials will not be published, and due effort will be made to conceal their identity, but that anonymity cannot be guaranteed.

\section{REFERENCES}

1. Zhu N, Zhang D, Wang W, Li X, Yang B, Son J, et al. A novel coronavirus from patients with pneumonia in China. 2019. N Engl J Med. 2020;382:727-33.

2. Lu R, Zhao X, Li J, Niu P, Yang B, Wu H, et al. Genomic characterization, and epidemiology of 2019 novel coronavirus: implications for virus origins and receptor binding. Lancet, 2020;395:565-74.

3. Daneshgaran G, Dubin DP, Gould DJ. Cutaneous manifestations of COVID-19: An Evidence-based review. Am J Clin Dermatol, 2020;21:627-39.

4. Abreu-Velez AM, Upegui-Zapata YA, Valencia-Yepes CA, UpeguiQuiceno E, Mesa-Herrera NR, Jiménez-Echavarria AM, et al. Membrane attack complex (C5b-9 complex or Mac), is strongly present in lesional skin from patients with endemic pemphigus foliaceus in El Bagre, Colombia. J Cutan Pathol. 2019;46:925-9.

5. Tang K, Wang Y, Zhang H, Zheng Q, Fang R, Sun Q. Cutaneous manifestations of the Coronavirus Disease 2019 (COVID-19): A brief review. Dermatol Ther. 2020:e13528.

6. Xu R, Zhou Y, Cai L, Wang L, Han J, Yang X, et al. Co-reactivation of the human herpesvirus alpha subfamily (herpes simplex virus-1 and varicella zoster virus) in a critically ill patient with COVID-19. Br J Dermatol. 2020;183:1145-7.

7. Wang B, Guo S, Yao Y, Li Y, Zhang G. Dermatologists may need to pay more attention to herpes zoster during the pandemic of COVID-19. Infect Dis (Lond). 2020;52:917-18.

8. Saati A, Al-Husayni F, Malibari AA, Bogari AA, Maher Alharbi M. Herpes zoster co-infection in an immunocompetent patient with COVID-19. Cureus, 2020;12:e8998.

9. Català A, Galván Casas, Carretero Hernadez G, Garcia-Doval I. Vesicular eruption in COVID-19 - to exclude varicella: reply from the authors. Br J Dermatol, 2020;183:791.

10. Moderbacher CR, Ramirez SI, Dan JM, Grifoni A, Hastie KM, Daniela Weiskopf D, et al. Antigen-specific adaptive immunity to SARS-CoV-2 in acute COVID-19 and associations with age and disease severity. Cell. 2020;183:996-1012.e19.

11. Shukla D, Spear PG. Herpesviruses and heparan sulfate: an intimate relationship in aid of viral entry. J Clin Invest. 2001;108:503-10.

12. Jacquet A, Haumont M, Chellun D, Massaer M, Tufaro F, A Bollen A, et al. The varicella zoster virus glycoprotein $\mathrm{B}(\mathrm{gB})$ plays a role in virus binding to cell surface heparan sulfate proteoglycans. Virus Res. 1998;53:197-7.

13. Bacsa S, Karasneh G, Dosa S, Liu J, Valyi-Nagy T, Shukla D. Syndecan-1 and syndecan-2 play key roles in herpes simplex virus type-1 infection. J Gen Virol. 2011;92:733-43.

14. Übelhart R, Hug E, Bach MP, Thomas Wossning T, Dühren-von Minden M, Anselm H C Horn AHC et al. Responsiveness of B cells is regulated by the hinge region of IgD. Nat Immunol. 2015;16:534-43.

Copyright by Ana Maria Abreu Velez, et al. This is an open-access article distributed under the terms of the Creative Commons Attribution License, which permits unrestricted use, distribution, and reproduction in any medium, provided the original author and source are credited.

Source of Support: Georgia Dermatopathology Associates, Atlanta, GA. Conflict of Interest: None declared. 